\title{
Targeted sequencing of NOTCH signaling pathway genes and association analysis of variants correlated with mandibular prognathism
}

\author{
Xianzhuo Han ${ }^{1 \dagger}$, Xueyan Xiong ${ }^{2 \dagger}$, Xiujuan Shi ${ }^{3^{*}}$, Fengshan Chen ${ }^{1^{*}}$ and Yongming $\mathrm{Li}^{1^{*}}$
}

\begin{abstract}
Introduction: The purpose of this study was to systematically identify variants in NOTCH signaling pathway genes that correlate with mandibular prognathism (MP) in the general Chinese population.

Methods: Targeted sequencing of NOTCH signaling pathway genes was conducted in 199 MP individuals and 197 class I malocclusion control individuals. The associations of common and rare variants with MP, cephalometric parameters, and continuous cephalometric phenotypes were analyzed by principal component (PC) analysis. The associations between rare variants and MP were tested for each gene.

Results: Six SNPS, including rs415929, rs520688, and rs423023 in an exonic region of NOTCH4; rs1044006 in an exonic region of NOTCH3; rs 1051415 in an exonic region of JAG1; and rs75236173 in the $3^{\prime}$-untranslated region (3'-UTR) of NUMB were associated with MP $(P<0.05)$. One common variant, rs 1051415, in an exonic region of JAG1 was significantly related to PC1 $\left(P=3.608 \times 10^{-4}\right)$, which explained $24.3 \%$ of the overall phenotypic variation observed and corresponded to the sagittal mandibular position towards the maxilla, ranging from a posterior positioned mandible to an anterior positioned mandible. Additionally, 41 other variants were associated with $P C 1-5(P<0.05)$. With respect to rare variant analysis, variants within the EP300, NCOR2, and PSEN2 gene showed an association with MP $(t<0.05)$.
\end{abstract}

Conclusions: An association between NOTCH signaling pathway genes and MP has been identified.

Keywords: Targeted sequencing, NOTCH signaling pathway, Association analysis, Mandibular prognathism

\section{Background}

Mandibular prognathism (MP) is characterized by excessive mandibular growth with or without deficient maxillary growth [1]. It causes an unpleasant facial profile and decreases masticatory efficiency $[2,3]$. Prevalence of MP

\footnotetext{
* Correspondence: xiujuansh@tongji.edu.cn; chenfs2017@sina.com; 1727039279@qq.com

'Xianzhuo Han and Xueyan Xiong contributed equally to this work.

${ }^{3}$ Tongji University School of Medicine, Shanghai, China

'Department of Orthodontics, School and Hospital of Stomatology, Shanghai Engineering Research Center of Tooth Restoration and Regeneration, Tongji University, Middle Yanchang Road, 399 Shanghai, P.R. China

Full list of author information is available at the end of the article
}

varies according to population; it is higher in Asians (approximately up to 15\%) and lower in Caucasians (approximately 1\%) [4]. Environmental factors have been found to contribute to the development of MP, such as enlarged tonsils, difficulty in nasal breathing, congenital anatomic defects, and diseases of the pituitary gland [5]. A familial aggregation phenomenon suggests that heredity plays a major role in the etiology of MP. The inheritance pattern of MP is complex, and controversial findings have been reported suggesting an autosomal recessive inheritance, an autosomal dominant inheritance, a dominant inheritance pattern with incomplete

C C The Author(s). 2021 Open Access This article is licensed under a Creative Commons Attribution 4.0 International License, which permits use, sharing, adaptation, distribution and reproduction in any medium or format, as long as you give appropriate credit to the original author(s) and the source, provide a link to the Creative Commons licence, and indicate if changes were made. The images or other third party material in this article are included in the article's Creative Commons licence, unless indicated otherwise in a credit line to the material. If material is not included in the article's Creative Commons licence and your intended use is not permitted by statutory regulation or exceeds the permitted use, you will need to obtain permission directly from the copyright holder. To view a copy of this licence, visit http://creativecommons.org/licenses/by/4.0/ The Creative Commons Public Domain Dedication waiver (http://creativecommons.org/publicdomain/zero/1.0/) applies to the data made available in this article, unless otherwise stated in a credit line to the data. 
penetrance, or a polygenic threshold model for inheritance [6].

Genetic studies have focused on MP. A few genome linkage scans and a genome wide association study (GWAS) identified some loci related to MP, including the first susceptibility loci,1p36, 6q25, and $19 \mathrm{p} 13.2$ in Korean and Japanese families [6]; 11q22, 12q13.3, and 12q23 in Hispanic families; and 14q24.3-31.2 in Han Chinese pedigrees $[7,8]$. Cartilage matrix protein (Matrilin-1) and erythrocyte membrane protein band 4.1 (EPB41) within the $1 \mathrm{p} 36$ locus were identified as potential genes underlying MP $[9,10]$. Myosin $1 \mathrm{H}(\mathrm{MYO} 1 \mathrm{H})$ located on 12q24.11, which is near $12 \mathrm{q} 23$, was suggested to be related to MP [11]. Rio de Janeiro et al. demonstrated that $M Y O 1 H$ (rs10850110 AlG) was associated with an increasing risk for the mandibular prognathism phenotype in a Brazilian population [12]. A microsatellite genome-wide association study in a Japanese population suggested that 2 loci-- $1 \mathrm{q} 32.2$ and $1 \mathrm{p} 22.3$, and two genes--PLXNA2 and SSX2IP, were associated with MP [13]. Recently, our group has been conducting genetic studies of MP and has identified a novel mutation in $F G F 23$, c. $35 \mathrm{C}>\mathrm{A}$, that is strongly associated with MP [14]. Even considering these findings, the genetic factors associated with MP are not fully understood, leading to motivation to search for new candidate genes.

MP is a developmental malformation underling a craniofacial osteogenesis disorder. The genetic mechanisms of craniofacial development have been elucidated, and the FGF, BMP, SHH, and NOTCH signaling pathways as well as many other signal pathways play critical roles [15]. The mandibular condyle, a growth center of the mandible, undergoes endochondral bone formation that is controlled by regulatory factors. Cells in its proliferative layer express the transcription factor Sox9. Sox9 then regulates chondrocytes to synthesize type II collagen, and then, chondrocytes progress towards hypertrophy and secrete type X collagen for the hypertrophic cartilage destined for endochondral ossification [16].

The NOTCH signaling pathway plays a key role in skeletal development and bone remodeling. It regulates morphogenesis during development by establishing and maintaining cellular boundaries that subdivide an originally homogeneous tissue field into distinct cell populations. In vertebrates, NOTCH signal establishes the anterior-posterior polarity of each somite [17-19]. In mandibular condylar cartilage (MCC), NOTCH receptors and ligands are localized to the chondroprogenitor and perichondrial layers. NOTCH signaling promotes angiogenesis in the bone endothelium, which involves the paracrine release of Sox9 and VEGF by endothelial cells that are required for chondrocyte maturation [20]. Lower expression of $\mathrm{NOTCH}$ in the MCC decreases the proliferation of chondrocytes and promotes differentiation (Sox9 expression) [21]. Overexpression of the Notch1 intracellular domain (N1-ICD) significantly increases BMP2-mediated induction of alkaline phosphatase (ALP) activity and calcification of human aortic smooth muscle cells [22]. Other genes of the NOTCH signaling pathway, including Lfng, Heyl, and Hesl, can be regulated by $B M P-2$ and TGF- $\beta$ as well [23]. Forward reposition of the mandible with functional appliances can trigger the expression of Ihh and Pthlh, which promote mesenchymal cell differentiation and proliferation. Meanwhile, the IHH and PTHLH proteins act as mediators of mechanotransduction to promote growth of the cartilage [24]. Mice with cartilage-specific deletion of Notch display a strong impairment in columnar zone chondrocyte responsiveness and significant incensement of perichondrial osteoblast responsiveness to $I H H$, which coincided with an advanced osteoblast differentiation and bone formation phenotype $[25,26]$.

Gain- or loss-of-function mutations in $\mathrm{NOTCH}$ signaling pathway genes result in different types of skeletal diseases. These mutations are associated with spondylocostal dysostosis, spondylothoracic dysostosis and recessive brachydactyly, diseases characterized by skeletal patterning defects. Notch is also highly expressed in osteosarcoma and in breast cancer cells that form osteolytic bone metastases. Wnt1Cre;RosaNotch embryos exhibitneural tube closure defects, along with exencephaly and micrognathia [27]. HajduCheney syndrome, which is driven by the production of a stabilized NOTCH2 lacking a functional PEST (peptide sequence that is rich in proline $(\mathrm{P})$, glutamic acid (E), serine $(\mathrm{S})$, and threonine $(\mathrm{T})$ ) degradation domain, is caused by gain-of-function mutations in NOTCH2 [28]. This disorder is characterized by short stature, bowing of the long bones, vertebral anomalies and facial features including hypertelorism, bushy eyebrows, micrognathia, small mouth with dental anomalies and low-set ears. Alagille syndrome is a genetic disorder clinically defined by hepatic bile duct paucity, cholestasis, cardiac, skeletal, and ophthalmologic manifestations [28]. It is caused by haploinsufficiency of JAG1 ( $94 \%$ of patients) or by mutations in NOTCH 2 (2\% of patients) and is considered to be a Notch loss-of-function phenotype [29]. Adams-Oliver syndrome is diagnosed based on terminal transverse limb malformations, an absence of skin and a partial absence of skull bones. This rare genetic disorder can be autosomal dominant, autosomal recessive or caused by de novo mutations. The autosomal dominant forms are caused by mutations in NOTCH1, RBPJ or DLL4, all of which are NOTCH pathway components $[30,31]$. It is reasonable to hypothesize that the variants of genes in the NOTCH signaling pathway play an important role in MP pathogenesis. 
Rare genes causing complex diseases provide wedges of understanding to crack open whole metabolic pathways and uncovering new candidate genes for further genetic disease study [32]. Genes that are linked to rare syndromes can provide insight into the comprehension of isolated traits [12].Rare diseases can serve as models for genetic susceptibility of more common traits in the population [33], which gave our group the idea that there is a relationship between the $\mathrm{NOTCH}$ signaling pathway and maxillofacial malformation. The purpose of this study was to systematically identify variants of the genes in the NOTCH signaling pathway that predispose one to $\mathrm{MP}$ in the general Chinese population.

\section{Materials and methods}

\section{Participants}

This case-control study included 199 MP patients (mean age, $23.6 \pm 3.2$ yrs.; 86 males) and 197control individuals with Class I occlusion (

mean age, $26.8 \pm 2.6$ yrs.; 86 males). All subjects were recruited from registered patients who underwent orthodontic treatment from January 2015 to September 2016, This study was approved by the Human Ethics Committee and was conducted according to Declaration of Helsinki principles, and all participants gave written informed consent. The statistical power was computed using Piface (Version 1.76, https://homepage.divms. uiowa.edu/ rlenth/Power/). A positive allele can be detected when the odds ratio (OR) is greater than 3 with the sample size in this study, under the assumption of $1 \%$ (minor allele frequency) MAF, 5\% type I error rate $(\alpha)$, and $80 \%$ statistical power.

The occlusal relationship of individuals was evaluated with a dental study model or visual inspection and was confirmed by digital tracing of a lateral cephalogram. Patients with facial trauma, congenital abnormalities (such as cleft lip and palate), or endocrinological diseases were not included in the study. Those that had undergone previous orthodontic treatment were also excluded from the present study. All the participants were of unrelated Chinese Han ethnicity.

The assessment of the eligible subjects consisted of diagnosing by digital tracings of lateral cephalograms, which were taken using dental X-ray equipment (Veraviewepocs X550, Kyoto, Japan).

The inclusion criteria for MP were defined as a cephalometric ANB angle (Point A-nasion- Point B) of centric jaw relationship less than $0^{\circ}[6]$ and a negative Wits appraisal greater than $-2.0 \mathrm{~mm}$ [11]. The inclusion criteria for normalskeletal Class I was an ANB angle range from 0.3 to 4.8 degrees and a Wits appraisal between 1.3 and $2.4 \mathrm{~mm}$ (Table 1). All participants provided a blood sample from which DNA could be extracted. Genomic DNA from EDTA-anticoagulated peripheral blood was extracted using a QIAamp DNA Blood Kit (QIAG ENE GmbH, Hilden, Germany) according to the manufacturer's instructions. All the samples were stored at < $-80^{\circ} \mathrm{C}$ until analysis [34].

\section{Cephalometric analysis}

Two independent orthodontists performed cephalometric tracing using NemoCeph NX software (version 6.0, Nemotec, Madrid, Spain) at 2-week intervals. Twentyseven skeletal landmarks and 9 soft landmarks were traced on a lateral cephalogram of each participant (Table S1). Then, sixty-one cephalometric parameters were digitally generated and used for phenotyping study (Table S2). The interrater and intrarater agreement was then tested by an intraclass correlation method as described previously [35].

\section{Targeted region sequencing and data analysis}

In this study, the coding and flanking regions of the 27 genes (total length: approximately $151,344 \mathrm{bp}$ ) in the NOTCH/Delta1 signaling pathway were selected and sequenced (Table S3). A customized NimbleGen capture array (Roche-NimbleGen Inc. Madison, WI, Custom probes details are in Table S4) was used to capture the targeted regions according to the manufactory's protocols. Then, the sequencing was performed using an Illumina Hiseq2000 platform (Illumina Inc., San Diego, $\mathrm{CA})$. The original reads were then aligned to the human reference genome (hg19) using the Burrows-Wheeler Alignment tool v0.7.1 (http://maq.sourceforge.net) to generate a binary sequence alignment/mapping file with various mapping information. Then, duplicate reads were removed, and alignments were processed with Picard v1.137 (Https://github.com/broadinstitute/picard/ releases) and the Genome Analysis Toolkit v3.4-46. The coverage, average quality, and global depth of the alignment read according to the stack file were generated with SAMtools v1.2 $(P<0.05)$. Variants were called using SNPTools and annotated using the ANNOVAR software package (http://www.openbioinformatics.org/ annovar/). Possible pathogenic effects of the missense mutations were evaluated using MutationTaster software

Table 1 Demographical characteristics of the cases and controls

\begin{tabular}{lllll}
\hline & Male/Female & Mean age (SD) & Mean ANB( ${ }^{\circ}$, SD) & Mean wits appraisal (mm, SD) \\
\hline Case & $39 / 57$ & $20.49 \pm 6.02$ & $-3.14 \pm 2.23$ \\
Control & $44 / 59$ & $21.24 \pm 6.19$ & $2.93 \pm 1.32$ & $-4.24 \pm 3.89$ \\
\hline
\end{tabular}


(http://www.mutationtaster.org). Indels (insertion/deletion) were verified manually. Six randomized samples (3 cases and 3 controls) were analyzed (Figure S1), and Sanger sequencing of the positive SNPs in this study was also carried out.

\section{Statistical analysis}

Each SNP was evaluated independently in the cases and the controls for Hardy-Weinberg equilibrium (HWE) analysis (http://www.oege.org/software/hwe). For the common variation (MAF $\geq 1 \%$ ), the genotyping distributions and allele frequencies of the SNPs between the cases and controls were compared using a Pearson chisquare test or Fisher's exact test (when the expected count was less than 5). The effect of variants on the MP odds ratio (OR) and 95\% confidence interval (CI) was tested by logistic regression analysis. After age and gender adjustments, a linear regression analysis was performed to determine the association between each cephalometric parameter and common variants. Principle component analysis was used to decrease the dimensions of the phenotypes. Principle components (PCs) explaining more than 5\% of the total variance of the cephalometric parameters data were used to test the association with variants by linear regression. For rare variants (MAF $<1 \%$ ), a $t$-test was performed to compare cumulative exonic variants in each gene region of cases and controls. In addition, the Combined Annotation Dependent Depletion (CADD) score was used as a weight factor in this test. All statistical analyses were performed using SAS version 9.2 (SAS Institute Inc., Cary, NC) with a double-headed $P$-value $<0.05$ considered statistically significant.

\section{Resultss}

In our study, 27 skeletal landmarks and 9 soft landmarks were traced on a lateral cephalogram of each participant at least 2 weeks apart (by one of the co-first authors) to assess the intrarater reliability. A subsample of 15 cephalometric radiographs was chosen randomly and traced by the other rater (the other co-first author) to assess interrater reliability. The reliability of the landmark location was determined by intraclass correlation methods (ICC). Our results showed that the intrarater reliability ranged from ICC $=89.21 \%$ to $\mathrm{ICC}=99.98 \%$, while the interrater reliability ranged from $\mathrm{ICC}=86.33 \%$ to $\mathrm{ICC}=99.57 \%$. Both values were generally acceptable $(\geq 85 \%)$ [35].

\section{Targeted sequencing data}

The average sequencing coverage was $67 \times$ (interquartile range $43-87 \times$ ). The concordance of the variants called in duplicate samples was more than $99 \%$. The variants with calling rates less than $95 \%$ or inconsistent with Hardy-Weinberg equilibrium $(P<0.01)$ in the control group were removed. Based on the MAF of the variants tested in the control group, the retained variants were then classified into 2 groups: common variants (MAF $\geq$ $0.01)$ and rare variants $(\mathrm{MAF}<0.01)$. Overall, 1520 variants were identified across all sequenced individuals in the targeted regions, including 337 common variants and 1183 rare variants.

\section{Association analysis of common variants}

Among the 337 common variants, we presented only those variants significantly associated with $\mathrm{MP}$ and PC that explained more than $5 \%$ of the facial variation. The Sanger sequencing results for the positive SNPs in this study were in accordance with the raw results (Fig. 1). No common variants within the 27 genes were significantly associated with MP after Bonferroni correction for multiple testing (cut-off $P$ value $=0.05 / 337=1.48 \times$ $\left.10^{-4}\right)$. Only 6 SNPs reached nominal significance $(P<$ $0.05)$, including rs415929, rs520688, and rs423023 in an exonic region of $\mathrm{NOTCH} 4$; rs1044006 in an exonic region of NOTCH3; rs1051415 in an exonic region of JAG1; and rs75236173 in the 3 '-UTR of NUMB. The genotypic and allelic frequencies at rs415929, rs423023, rs520688, rs1044006, rs1051415, and rs75236173 were significantly different between the case and control groups. The C allele of rs415929, the C allele of rs423023, the $C$ allele of rs520688, the $C$ allele of rs1044006, the $\mathrm{T}$ allele of rs1051415, and the $\mathrm{T}$ allele of rs75236173, increased the risk of MP, with OR ratios of $1.503(1.039,2.176), 1.480(1.022,2.144), 1.445(1.001$, $2.085), 0.711(0.506,0.9989), 1.708(1.044,2.784)$, and $1.417(1.007,1.995)$, respectively (Table 2).

Some associations between common variants and each cephalometric parameter were also detected. rs3125001 in NOTCH1 was negatively associated with inferior facial height $(P<0.01)$. rs372504208 in NOTCH2 is a frameshift deletion (c.17_18delCC). It was found to be negatively associated with articular angle $(P<0.05)$. rs1044009 in NOTCH3 was associated with the APDI index (NP-AB) and the ANB angle $(P<0.05)$. rs386591752 in NOTCH4 was associated with the ANB angle, wits appraisal, APDI index, facial convexity and overjet $(P<0.01)$.rs1051415 in JAG1 was associated with the anterior-posterior facial height ratio $(P<0.01)$. rs2272591 and rs10149229 in JAG2 were negatively correlated with mandibular body length $(P<0.01)$. rs1057744 inJAG2 was negatively correlated with facial angle and the $\mathrm{Y}$ axis $(P<0.05)$. rs2304223 in DLL3 was negatively associated with facial angle $(P<0.05)$. rs20551 in EP300 was negatively associated with mid-face length $(P<0.05)$ (Table 3$)$.

The results of the PCA revealed that 5 PCs accounted for $72.8 \%$ of the total variance, and each of them represented $24.3,17.5,14,9.7$, and $7.3 \%$ of the total variance, 


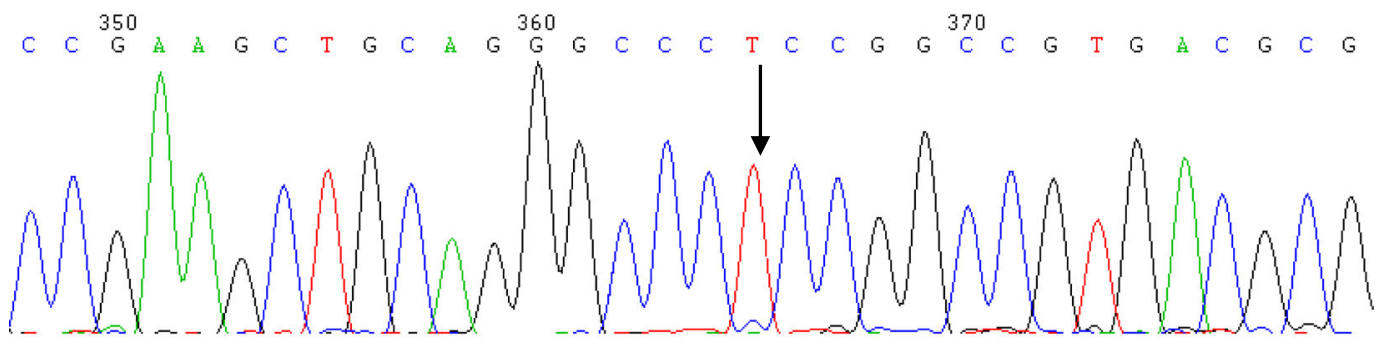

rs75236173.

A8

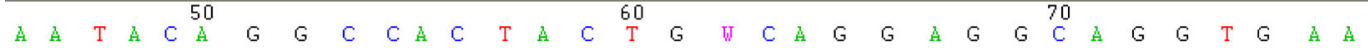

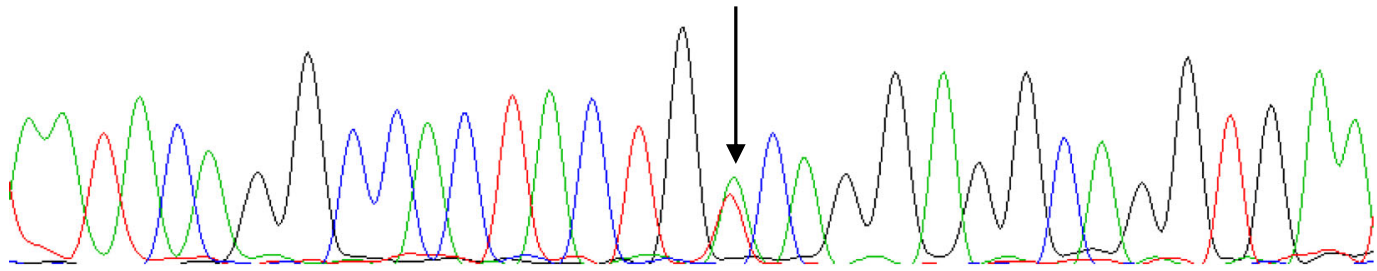

A42

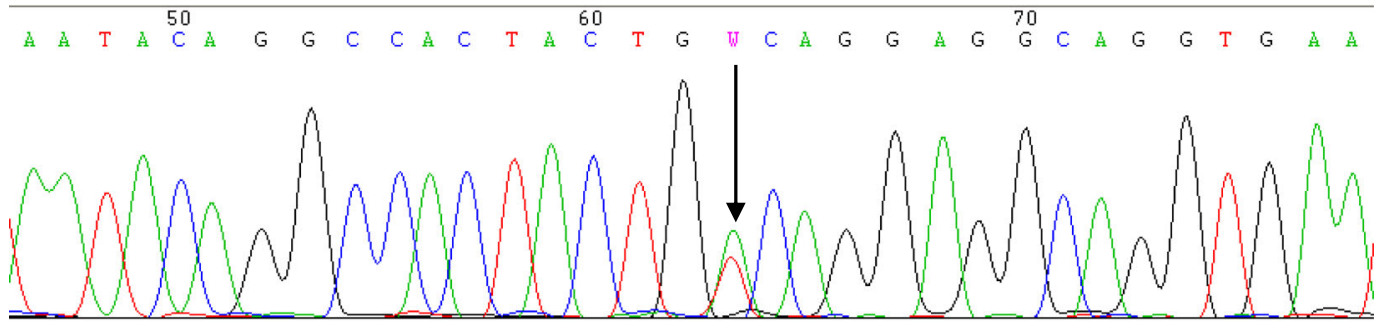

A43

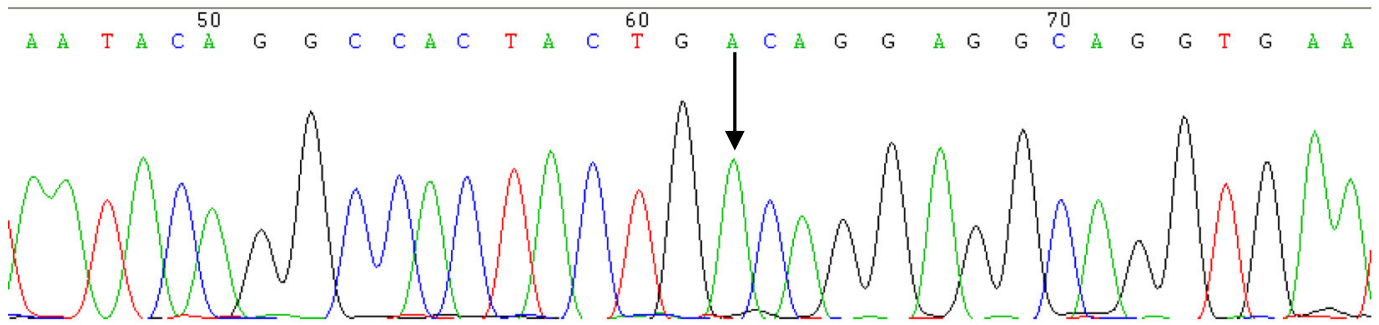

$\mathrm{CO2}$

A A A $\quad \begin{aligned} & 50 \\ & \text { A }\end{aligned}$

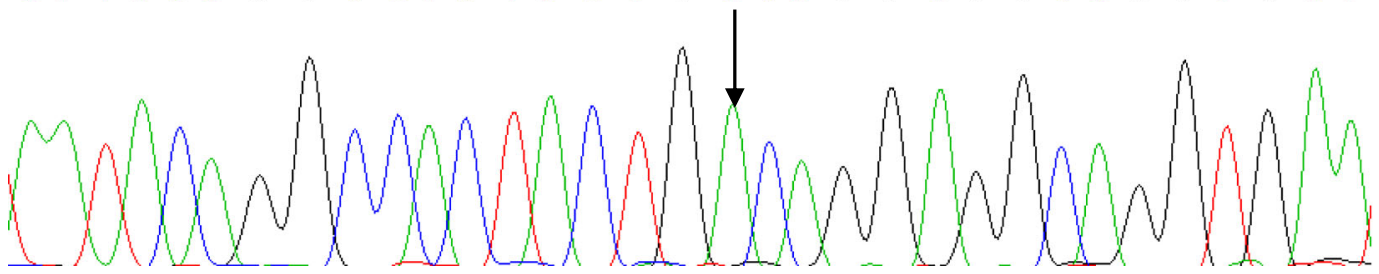

$\mathrm{CO3}$

Fig. 1 Three SNPS (rs1051415 in an exonic region of JAG1; rs75236173 in the 3'-UTR of NUMB; rs1044006 in an exonic region of NOTCH3) in six randomly selecting samples (including three cases and three controls) were validated by Sanger sequencing. The three cases were A8, A42 and A43, while the three control samples were $\mathrm{C} 02, \mathrm{C} 03$ and $\mathrm{C} 8$. The black arrows represent the polymorphism sites 
Table 2 The associations between SNPs identified in NOTCH signaling pathway genes and MP

\begin{tabular}{|c|c|c|c|c|c|c|c|}
\hline \multirow[t]{2}{*}{ SNP-Gene-Function } & \multicolumn{4}{|c|}{ Genotype/allele } & \multicolumn{2}{|l|}{ Logistic regression } & \multirow{2}{*}{$\begin{array}{l}\text { Statistical } \\
\text { Power(\%) }\end{array}$} \\
\hline & & Cases & Controls & $P$ & $\mathrm{OR}(95 \% \mathrm{Cl})$ & $P$ & \\
\hline \multirow[t]{4}{*}{ rs415929-NOTCH4-EXON } & $\pi$ & $126(63.3)$ & $142(72.1)$ & 0.075 & $1.503(1.039-2.176)$ & 0.030 & 39.8 \\
\hline & $\mathrm{TC}$ & $64(32.2)$ & $52(26.4)$ & & & & \\
\hline & $\mathrm{CC}$ & $9(4.5)$ & $3(1.5)$ & & & & \\
\hline & $\mathrm{T}: \mathrm{C}$ & 79.4:20.6 & $85.3: 14.7$ & 0.280 & & & \\
\hline \multirow[t]{4}{*}{ rs105415-JAG1-EXON } & $\mathrm{CC}$ & $156(78.4)$ & $171(86.8)$ & 0.087 & $1.708(1.044-2.784)$ & 0.031 & 33.91 \\
\hline & $\mathrm{CT}$ & $40(20.1)$ & $24(12.2)$ & & & & \\
\hline & $\pi$ & $3(1.5)$ & $2(1.0)$ & & & & \\
\hline & C:T & $88.4: 11.6$ & $92.9: 7.1$ & 0.280 & & & \\
\hline \multirow[t]{4}{*}{ rs423023-NOTCH4-EXON } & GG & $126(63.3)$ & $142(72.1)$ & 0.097 & $1.480(1.022-2.144)$ & 0.037 & 32.2 \\
\hline & GC & $65(32.7)$ & $52(26.4)$ & & & & \\
\hline & $\mathrm{CC}$ & $8(4.0)$ & $8(4.1)$ & & & & \\
\hline & $\mathrm{G}: \mathrm{C}$ & 79.7:20.4 & $85.3: 14.7$ & 0.290 & & & \\
\hline \multirow[t]{4}{*}{ rs7523617-NUMB-UTR3 } & $\mathrm{AA}$ & $111(55.8)$ & $132(67.0)$ & 0.066 & 1.417 (1.007-1.995) & 0.045 & 30.05 \\
\hline & AT & 79 (39.7) & $57(28.9)$ & & & & \\
\hline & $\pi$ & $9(4.5)$ & $8(4.1)$ & & & & \\
\hline & $A: T$ & $75.6: 24.4$ & $81.5: 18.5$ & 0.310 & & & \\
\hline \multirow[t]{4}{*}{ rs520688-NOTCH4-EXON } & $\pi$ & $126(63.3)$ & $141(71.6)$ & 0.140 & $1.445(1.001-2.085)$ & 0.049 & 29.06 \\
\hline & $\mathrm{TC}$ & $64(32.2)$ & $52(26.4)$ & & & & \\
\hline & $\mathrm{CC}$ & $9(4.5)$ & $4(2)$ & & & & \\
\hline & $\mathrm{T}: \mathrm{C}$ & 79.4:20.6 & 84.8:15.2 & 0.320 & & & \\
\hline \multirow[t]{4}{*}{ rs1044006-NOTCH3-EXON } & $\mathrm{CC}$ & $134(67.3)$ & $116(58.9)$ & 0.170 & $0.711(0.506-0.999)$ & 0.049 & 29.01 \\
\hline & $\mathrm{CT}$ & $55(27.6)$ & $65(33.0)$ & & & & \\
\hline & $\pi$ & $10(5.1)$ & $16(8.1)$ & & & & \\
\hline & C:T & 81.2:18.8 & $75.4: 24.6$ & 0.320 & & & \\
\hline
\end{tabular}

respectively (Fig. 2a, Table S5). A common variant (rs1051415; $P<0.01)$ in an exonic region of the JAG1 gene associated with PC1 was highly suggestive of MP. This component correlated with the sagittal mandibular position toward maxilla ranging from a posterior positioned mandible to an anterior positioned mandible. Another common variant (rs10149229; $P<0.01)$ in an exonic region of JAG2 was associated with PC4, which captured the protrusion and inclination of the lower and upper incisor. This variant was also associated with PC2, which mainly captured mandibular shape and size ranging from a short mandibular length, a short middle and posterior facial height to a long mandibular length, and a long middle and posterior facial height, although the associations were not significant after multiple corrections. rs915894 $(P<0.01)$ in an exonic region of NOTCH4, which is a nonsynonymous SNV, was associated with PC3 and mainly referred to the vertical and sagittal positions of the mandible relative to the cranial base. (Fig. 2b).
We also detected 4 other SNPs associated with PC1, 11 other SNPs associated with PC2, 6 other SNPs associated with PC3, and 16 other SNPs associated with PC4, with nominal significance $(P<0.05)$. In addition, 6 other SNPs associated with PC5, which captured the protrusion of facial soft tissue, were also identified at a $P<$ 0.05 significance level (Table 4).

\section{Association analysis of rare variants}

Compared with the controls, rare variants within the EP300, NCOR2, PSEN2 genes showed association with MP $(t<0.05)$ (Table S6).

\section{Discussion}

It is widely believed that genetic components play an important role in MP. To date, numerous chromosomal loci implicated in MP pathogenesis have been reported, and also a host of genes that predispose $\mathrm{MP}$, such as EPB41, MATN1, COL2A1, MYO1H, TGFB3, LTBP2, ADAMTS1, DUSP6, FGFR2, and FGF23. Most of these 
Table 3 Association between common variants and cephalometric parameter

\begin{tabular}{|c|c|c|c|c|c|}
\hline SNP-Gene-Function & A1/A2 & Phenotype parameters & BETA & SE & $P$ \\
\hline rs1051415-JAG1-exon & $C / T$ & Anterior-posterior facial height ratio (\%) & 2.50 & 0.86 & 0.0041 \\
\hline rs2272591-JAG2-exon & $A / G$ & Mandibular body length (mm) & -2.12 & 0.81 & 0.0093 \\
\hline rs10149229-JAG2-exon & $A / G$ & Mandibular body length (mm) & -2.80 & 0.82 & 0.00074 \\
\hline \multirow[t]{2}{*}{ rs1057744-JAG2-exon } & $C / T$ & Facial angle $\left(^{\circ}\right)$ & 34.08 & 15.41 & 0.028 \\
\hline & & $y$ axis $\left(^{\circ}\right)$ & 1.06 & 0.45 & 0.020 \\
\hline \multirow[t]{5}{*}{ rs386591752-NOTCH4-exon } & $\mathrm{T} / \mathrm{C}$ & ANB angle $\left(^{\circ}\right)$ & -1.58 & 0.48 & 0.0012 \\
\hline & & Wits appraisal (mm) & -2.42 & 0.72 & 0.0010 \\
\hline & & APDI index $\left(\left(^{\circ}\right)\right.$ & 1.79 & 0.64 & 0.0054 \\
\hline & & Facial convexity $\left({ }^{\circ}\right)$ & -3.65 & 1.10 & 0.0011 \\
\hline & & Overjet (mm) & -1.69 & 0.53 & 0.0017 \\
\hline rs372504208-NOTCH2-exon & $\mathrm{CGG} / \mathrm{C}$ & Articularangle (S-Ar-Go) $\left(^{\circ}\right)$ & -1.89 & 0.83 & 0.025 \\
\hline rs1044009-NOTCH3- exon & $\mathrm{G} / \mathrm{A}$ & APDI index $\left(\left(^{\circ}\right)\right.$ & -1.25 & 0.54 & 0.022 \\
\hline \multirow[t]{2}{*}{ rs2304223-DLL3-intron } & $C / G$ & ANB angle $\left(^{\circ}\right)$ & -0.73 & 0.34 & 0.033 \\
\hline & & Facial angle $\left(^{\circ}\right)$ & -51.70 & 24.83 & 0.039 \\
\hline rs20551-EP300-exon & $A / G$ & Midface length (mm) & -2.91 & 1.44 & 0.045 \\
\hline
\end{tabular}

studies were based on family linkage studies. However, the polygenic nature of MP makes it possible to study its genetic mechanism using a case-control design.

Although genetic linkage analysis and association studies have identified many genes and loci associated with $\mathrm{MP}$, the genes underlying the risk of MP in the general population remain elusive, prompting our search for new candidate genes. The NOTCH signaling pathway has been suggested to participate in craniofacial development and the regulation of TGFB3, FGFR2, and FGF23. We speculate that it is also involved in the etiology of MP. In the current study, we aimed to identify the association between variants in NOTCH signaling pathway genes and MP in MP cases and controls using a targeted sequencing strategy. We found some suspicious variants in these genes associated with MP.

According to association analysis of common variants, only 6 SNPs reached nominal significance $(P<0.05)$, including rs415929, rs520688, and rs423023 in an exonic region of NOTCH4; rs1051415 in an exonic region of JAG1; and rs1044006 in an exonic region of NOTCH3. As Bonferroni adjustment was not applied to most of the pairwise comparison, we acknowledge that the current significant findings are only suggestive and may be affected by Type I error.

Human JAGGED1 is the ligand for the NOTCH1 receptor. In a Mexican population, rs1051415 in the JAG1 gene was associated with Alagille syndrome (OMIM\#118450), which presents characteristic facial features including a pointed chin [36]. In this study, rs1051415 in an exonic region of JAG1 was associated with MP $(P<0.05)$. It was also associated with the anterior-posterior facial height ratio $(P<0.01)$. jagged- notch signaling contributes to the dorsal mandibular arch domain by repressing expression of genes associated with ossification. Deleting Jagged 1 in the cranial neural crest (CNC) causes (Wnt1-cre, Jag1 Flox/Flox) mice die at postnatal day 30 due to an inability to masticate, owing to jaw misalignment and poor occlusion, recapitulating the midfacial hypoplasia phenotype of Alagille syndrome [37]. Conditional inactivation of Jag1 in mouse NCCs leads to the development of a shortened maxilla [38]. Our results are consistent with these findings suggesting that JAG1 is associated with MP. The mutations in JAG1were associated with unilateral coronal craniosynostosis in humans. As the temporal and spatial patterns of $\mathrm{NOTCH}$ signaling expression are markedly different in the posterofrontal and sagittal sutures, Notch may contribute to craniosynostosis and then to the craniomaxillofacial growth [39].

rs10149229 in exon 26 of JAG2 was correlated with PC4, which captured the protrusion and inclination of the lower and upper incisor $(P<0.01)$. Four other SNPs in JAG2 were also identified: rs145952626 and rs741859in the $3^{\prime}$-UTR of JAG2 were correlated with PC2 $(P<0.01)$, which mainly correlated with a longer mandible length and a longer middle and posterior facial height. In a Brazil population, a strong association was observed by haplotype analyses containing rs1057744 polymorphism in cleft lip with or without cleft palate [40]. Mice with inactivated Jagged2 exhibit craniofacial defects including cleft palate [41]. Although mutations in the JAG2 gene have not been linked to any specific human diseases, homozygous Jag2 null mice display severe craniofacial defects, including cleft palates and fusion of the tongue with the palatal shelves. The potential 


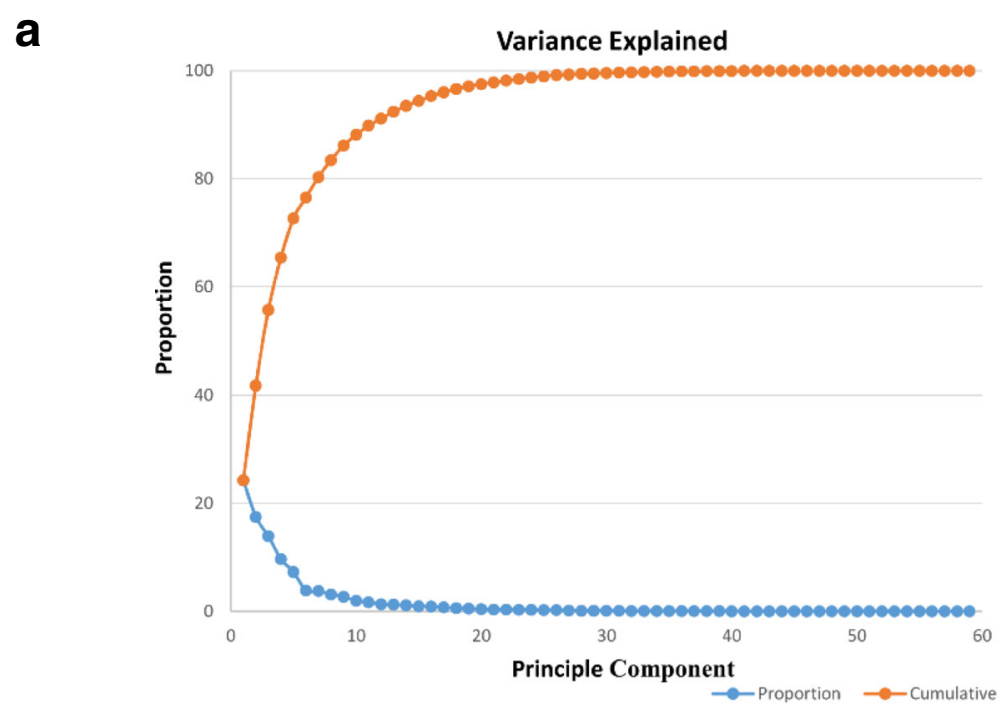

Principal Component Analyses. Five principal components accounted for $72.8 \%$ of the variation

\section{b}
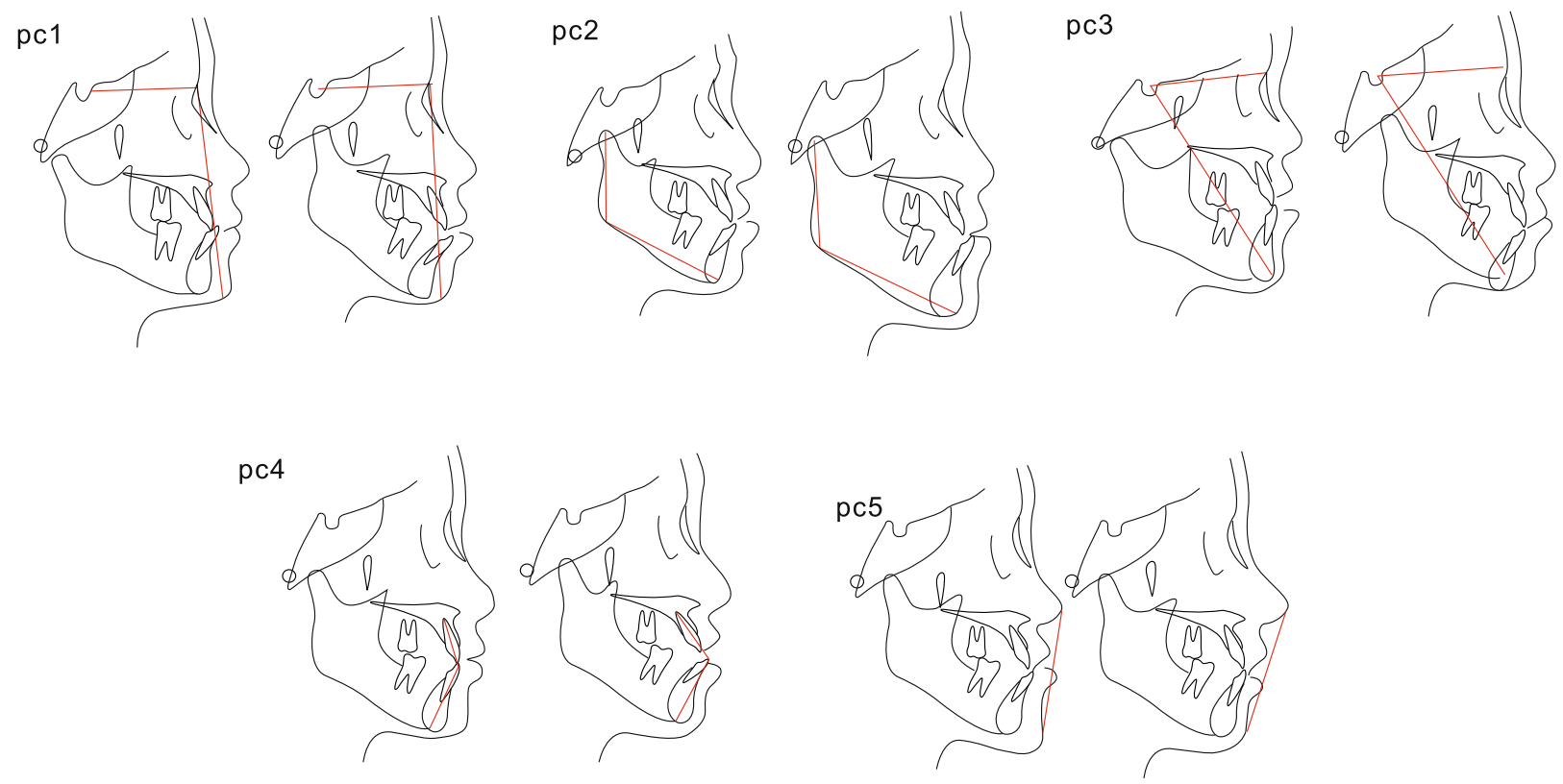

Examples of individuals at opposite extremes of the distributions for each of the 5 principal

\section{components.}

Fig. 2 Examples of individuals at opposite extremes of the distributions for each of the 5 principal components. PC1 explained $24.3 \%$ of the observed facial variation and corresponded to variations within the sagittal mandibular position toward maxilla. PC2 explained $17.5 \%$ of the observed facial variation and corresponded to mandibular shape and size. PC3 corresponded to the vertical and sagittal positions of the mandible relative to the cranial base. PC4 corresponded to the protrusion and inclination of the lower and upper incisors and explained $10 \%$ of the observed facial variation. PC5 corresponded to the protrusion of facial soft tissue and accounted for $7.3 \%$ of the variation

function of the JAG2 gene in maxillofacial development needs to be further studied.

rs10521 in an exonic region of NOTCH1 was associated with PC1 $(P<0.05)$. High levels of activated Notch1 were observed in the differentiating oral periderm and the lateral mandibular and maxillary processes [42]. NOTCH1 is localized primarily in the chondroprogenitor layer of the mandibular condylar cartilage (MCC). 
Table 4 Association between common variants and 5 PCs

\begin{tabular}{|c|c|c|c|c|c|c|c|}
\hline Trait & SNP & $\mathrm{A} 1 / \mathrm{A} 2$ & Gene & Fun & Beta & SE & $P$ \\
\hline PC1 & rs1051415 & $\mathrm{C} / \mathrm{T}$ & JAG1 & Exon/syn & -0.7298 & 0.1986 & 0.0003608 \\
\hline PC1 & rs7104987 & $\mathrm{A} / \mathrm{G}$ & MAML2 & UTR3 & 0.2938 & 0.1219 & 0.0175 \\
\hline PC1 & rs8383 & C/AGT & PSEN2 & Intronic & 0.2925 & 0.1303 & 0.02666 \\
\hline PC1 & rs7930268 & $\mathrm{T} / \mathrm{CG}$ & MAML2 & UTR3 & 0.2802 & 0.1254 & 0.02742 \\
\hline PC1 & rs2304214 & C/GT & DLL3 & Exon/syn & -0.4739 & 0.2129 & 0.02793 \\
\hline PC1 & rs2304223 & $C / G$ & DLL3 & Intronic & -0.4739 & 0.2129 & 0.02793 \\
\hline PC2 & rs1044009 & $\mathrm{G} / \mathrm{AC}$ & $\mathrm{NOTCH} 3$ & Exon/nonsyn & -0.2354 & 0.1136 & 0.0404 \\
\hline PC2 & rs741859 & $\mathrm{C} / \mathrm{T}$ & JAG2 & UTR3 & -0.3261 & 0.1231 & 0.009212 \\
\hline PC2 & rs957578869 & $\mathrm{G} / \mathrm{T}$ & JAG2 & UTR3 & 0.4257 & 0.1489 & 0.005034 \\
\hline PC2 & rs1177358515 & $\mathrm{G} / \mathrm{T}$ & EP300 & Intronic & 0.4909 & 0.1887 & 0.01049 \\
\hline PC2 & rs10149229 & $\mathrm{A} / \mathrm{CG}$ & JAG2 & Intronic & -0.3172 & 0.1222 & 0.01068 \\
\hline PC2 & rs2272591 & A/GT & JAG2 & Intronic & -0.3083 & 0.1211 & 0.01223 \\
\hline PC2 & rs6705408 & $\mathrm{C} / \mathrm{T}$ & ADAM17 & UTR3 & -0.4671 & 0.1949 & 0.01812 \\
\hline PC2 & rs2274185 & $C / G$ & NCSTN & Intronic & -0.3322 & 0.156 & 0.03528 \\
\hline PC2 & rs1106317 & A/GT & NCOR2 & Intronic & 0.2442 & 0.1159 & 0.03726 \\
\hline PC2 & rs9972231 & C/AGT & JAG2 & Intronic & 0.3294 & 0.1565 & 0.03748 \\
\hline PC2 & rs117649295 & $\mathrm{G} / \mathrm{A}$ & LFNG & UTR3 & -0.4966 & 0.2413 & 0.04184 \\
\hline PC2 & rs28386899 & $\mathrm{G} / \mathrm{A}$ & RFNG & UTR5 & 0.3577 & 0.1753 & 0.04354 \\
\hline PC3 & rs165935 & $\mathrm{C} / \mathrm{T}$ & PSEN1 & UTR3 & -0.3067 & 0.1388 & 0.02915 \\
\hline PC3 & rs6563 & $\mathrm{A} / \mathrm{CG}$ & NOTCH1 & UTR3 & 0.3215 & 0.1519 & 0.03641 \\
\hline PC3 & rs1055834488 & $\mathrm{G} / \mathrm{AC}$ & JAG1 & UTR5 & -0.3348 & 0.1637 & 0.04304 \\
\hline PC3 & rs10423702 & $\mathrm{T} / \mathrm{C}$ & NOTCH3 & Intronic & 0.3721 & 0.1822 & 0.0434 \\
\hline PC3 & rs1044009 & $\mathrm{G} / \mathrm{AC}$ & $\mathrm{NOTCH} 3$ & Exon/nonsyn & 0.3327 & 0.1496 & 0.02802 \\
\hline PC3 & rs1043996 & $\mathrm{G} / \mathrm{A}$ & NOTCH3 & Exon/syn & 0.3543 & 0.1314 & 0.008049 \\
\hline PC3 & rs915894 & $\mathrm{T} / \mathrm{G}$ & $\mathrm{NOTCH} 4$ & Exon/nonsyn & 0.3462 & 0.1313 & 0.009514 \\
\hline PC4 & rs1033583 & $\mathrm{T} / \mathrm{G}$ & DLL1 & UTR3 & -0.4583 & 0.1541 & 0.003572 \\
\hline PC4 & rs2272591 [ & $\mathrm{A} / \mathrm{GT}$ & JAG2 & Intronic & -0.3459 & 0.1345 & 0.01134 \\
\hline PC4 & rs3734776 & $\mathrm{C} / \mathrm{T}$ & DLL1 & Intronic & -0.3278 & 0.1281 & 0.01176 \\
\hline PC4 & rs3741513 & $\mathrm{T} / \mathrm{A}$ & NCOR2 & Exon/syn & -0.4064 & 0.1646 & 0.01499 \\
\hline PC4 & rs3134942 & $\mathrm{G} / \mathrm{T}$ & $\mathrm{NOTCH} 4$ & Exon/syn & -0.7543 & 0.3105 & 0.01664 \\
\hline PC4 & rs3134930 & $\mathrm{C} / \mathrm{T}$ & NOTCH4 & Intronic & -0.2993 & 0.1259 & 0.01907 \\
\hline PC4 & rs741859 & $C / T$ & JAG2 & UTR3 & -0.321 & 0.1376 & 0.02139 \\
\hline PC4 & rs1044507 & $\mathrm{A} / \mathrm{C}$ & $\mathrm{NOTCH} 4$ & Exon/syn & -0.7504 & 0.3249 & 0.02266 \\
\hline PC4 & rs7931870 & $\mathrm{A} / \mathrm{G}$ & MAML2 & Exon/syn & -0.3707 & 0.1676 & 0.02891 \\
\hline PC4 & rs2243396 & C/GT & DTX1 & Intronic & -0.3267 & 0.149 & 0.03034 \\
\hline PC4 & rs3134798 & $\mathrm{G} / \mathrm{ACT}$ & $\mathrm{NOTCH} 4$ & Intronic & 0.4612 & 0.2113 & 0.03109 \\
\hline PC4 & rs114763 & C/GT & SNW1 & Exon/syn & -0.2856 & 0.1331 & 0.03401 \\
\hline PC4 & rs422951 & $\mathrm{T} / \mathrm{C}$ & NOTCH4 & Exon/nonsyn & -0.423 & 0.1976 & 0.03435 \\
\hline PC4 & rs443198 & $\mathrm{A} / \mathrm{GT}$ & $\mathrm{NOTCH} 4$ & Exon/syn & 0.2815 & 0.1332 & 0.03666 \\
\hline PC4 & rs3823301 & $C / T$ & DLL1 & UTR5 & -0.3524 & 0.127 & 0.006446 \\
\hline PC4 & rs10149229 & $\mathrm{A} / \mathrm{G}$ & JAG2 & Exon/syn & -0.3708 & 0.1353 & 0.007108 \\
\hline PC4 & rs915894 & $\mathrm{T} / \mathrm{G}$ & $\mathrm{NOTCH} 4$ & Exon/nonsyn & 0.2567 & 0.1277 & 0.04663 \\
\hline PC5 & rs79129905 & $\mathrm{G} / \mathrm{A}$ & LFNG & UTR3 & -0.4519 & 0.1827 & 0.01481 \\
\hline PC5 & rs5758235 & $\mathrm{T} / \mathrm{C}$ & EP300 & Intronic & -0.3857 & 0.1426 & 0.007857 \\
\hline
\end{tabular}


Table 4 Association between common variants and 5 PCs (Continued)

\begin{tabular}{llllllll}
\hline Trait & SNP & A1/A2 & Gene & Fun & Beta & SE & P \\
\hline PC5 & rs753573114 & C/AT & EP300 & Intronic & -0.4273 & 0.1431 & 0.003452 \\
PC5 & rs3818120 & G/A & EP300 & intronic & -0.3576 & 0.1395 & 0.01162 \\
PC5 & rs20552 & T/ACG & EP300 & Exon/syn & 0.3761 & 0.1474 \\
PC5 & rs17002316 & T/C & EP300 & intronic & -0.3857 & 0.1426 & 0.01203 \\
\hline
\end{tabular}

Disruption of $\mathrm{NOTCH}$ signaling in MCC explants decreased proliferation and increased chondrocyte differentiation, and the actions of FGF-2 in MCC are mediated in part by $N O T C H$ signaling $[43,44]$.

rs372504208 in exon 1 of NOTCH2 is a frameshift deletion (c.17_18delCC) that was predicted to be diseasecausing according to MutationTaster [45]. It was negatively associated with articular angle $(P<0.05)$. NOTCH2 is known to be important for vertebrate cranial morphogenesis, especially mandible and tooth development [28]. Mutations in NOTCH2 are responsible for Hadju-Cheney syndrome (OMIM \#102500) and Alagille syndrome [46]. The contribution of $\mathrm{NOTCH} 2$ to MP needs to be elucidated in the future.

rs1044006 in an exonic region of NOTCH3 was associated with $\mathrm{MP}(P<0.05)$. rs1044009 in an exonic region of NOTCH3 was associated with PC2 $(P<0.05)$, which mainly indicated a longer mandible length and a longer middle and posterior facial height. This SNP was also negatively associated with APDI index, ANB and SNB angle $(P<0.05)$. Low masticatory loading inhibits the development of condylar cartilage and decreases expression of notch-1, notch-3, jagged-1 and delta-like-1 in rabbits [47]. Thus, there may be a relationship between condyle development and the NOTCH signaling pathway. In the mandibular torus, increased osteogenic differentiation of mesenchymal stem cells (MSCs) was associated with the suppression of NOTCH3 signaling and its downstream target genes, which may contribute partly to bone outgrowth in mandibular torus [48]. As $\mathrm{MP}$ is an overgrowth of bone, it is reasonable to speculate NOTCH3participates in the etiology of MP [49]. The potential function of the NOTCH3 gene in maxillofacial development needs to be studied further.

rs415929, rs520688, and rs423023 in an exonic region of NOTCH4 were associated with $\operatorname{MP}(P<0.05)$. rs915894 in NOTCH4 was associated with PC3,which mainly referred to the position of the mandible relative to the cranial base. rs386591752 in exon 6 of NOTCH4 was negatively associated with the relative relationship between the maxilla and the mandible, including the ANB angle, wits appraisal, APDI, facial convexity and overjet $(P<0.01)$, which are important clinical diagnosis standards for Class I, Class II, and Class III skeletal facial patterns [50]. NOTCH4 is a transmembrane protein that regulates interactions between adjacent neurons.
Multiple genetic association studies have associated NOTCH4 with rheumatoid arthritis (RA) [51]. rs915894 in exon 3 of NOTCH4 is modestly significantly associated with RA $(P<0.01)$ [52]. The temporomandibular joint (TMJ) is a synovial joint. Being a target of RA, TMJ shows aggrecan degradation in the cartilage when RA occurs $[53,54]$. As it contributes to cartilage injury and rebuilding, $\mathrm{NOTCH} 4$ may play a role in condyle cartilage metabolism, which needs further research. While $\mathrm{NOTCH} 4$ has been explored in regards to angiogenesis [55] and tumorigenesis [56], we think it is necessary to verify the function of NOTCH4 in craniofacial development. In addition, our results showed rs2304223 in an intron of $D L L 3$ was negatively associated with facialangle $(P<0.05)$. It was also associated with PC1 $(P<0.05)$, which depicted the sagittal mandibular position toward maxilla ranging from posterior positioned mandible to anterior positioned mandible. DLL3 encodes a member of the delta protein ligand family. Dll3-Notch1 double heterozygous mice display remarkable reduction of mandibular height and elongation of the maxillary hard palate [57]. Mutations in DLL3 cause autosomal recessive SCDO1 (OMIM\#277300).

A frameshift deletion in exon 2 of LFNG (c.135_ 138del:p.W45fs) was predicted to be disease causing by MutationTaster [58]. This mutation was negatively associated with facial taper $(P<0.05)$. It was also associated with PC3 $(P<0.05)$, which mainly referred to the vertical and sagittal positions of the mandible relative to the cranial base. LFNG is a member of the fringe gene family that encodes evolutionarily conserved glycosyltransferases that act in the NOTCH signaling pathway to define boundaries during embryonic development. While their genomic structure is distinct from other glycosyltransferases, these proteins lead to the elongation of O-linked fucose residues on the NOTCH protein, which alters NOTCH signaling. An LFNG product is predicted to be a single-pass type II Golgi membrane protein. Mutations in LFNG have been associated with autosomal recessive spondylocostal dysostosis type 3 (SCDO3) (OMIM\#609813). In $\mathrm{SCDO} 3$ patients, all vertebral bodies appear to show more severe segmentation defects [59]. As LFNG may contribute to bone development, further research would be needed to identify the effect on craniofacial morphogenesis.

There are common variants with moderate effects and rare variants that have a great influence on the complex 
traits of genes. In the case of a moderate effect size with an MAF of less than $0.5 \%$, an association study using total "mutation load" composite tests that compare the frequency of mutation to potentially similar functional effects in cases and controls is needed. Low frequency variants could have a substantial effective without showing clear Mendelian isolation and could substantially contribute to missing heritability [12]. In this research, to explore the effect of rare variants of genes in the NOTCH signaling pathway in MP pathogenesis, burden tests were performed to compare the cumulative exonic variants in each gene region of cases and controls. Combined Annotation Dependent Depletion (CADD) is a quantitative score integrating many diverse annotations together, which relates to diversity of alleles, functionality, pathogenicity, and the severity of diseases. The CADD score power weight was also included with our burden tests to verify different effects of each variant. This was the first time that burden testing was combined with CADD score, which was an effective method for evaluating the association between genes and the etiology of mandibular prognathism. Then the summing over the cumulative score in all loci of each gene in cases and controls was compared by independentsamples $\mathrm{T}$ test.

"association analysis of rare variants" may also be affected by Type I error. In this study, rare variants in EP300 were related to MP $(P<0.05)$. In addition, rs20551 in exon 15 of EP300 was negatively associated with mid-face length $(P<0.05)$. EP300 is vital in cell proliferation and differentiation. It mediates $c A M P$-gene regulation by binding specifically to phosphorylated CREB protein. EP300 has also been identified as a coactivator of $H I F 1 A$, which plays a role in the stimulation of hypoxia-induced genes such as VEGF. Mutations in EP300 are a rare cause of Rubinstein-Taybi syndrome (RSTS) (OMIM\#180849). RSTS is mainly characterized by growth delays, craniofacial features (i.e., downslanting palpebral fissures, pouting lower lip, dental crowding, micrognathia and dysplastic), and skeletal abnormalities including broad or duplicated distal phalanges of thumbs and halluces [60].

According to the recommendations of a genetic association study, we applied a strict multiple testing correction. However, the Bonferroni adjustment can lead to a loss of true association because Class I errors cannot be reduced without increasing Type II errors, which does not guarantee a careful explanation of the results [61]. Although most of these effects didn't survive multiple testing correction, our results may also be suggestive. Mandibular prognathism (MP) has long been considered a complicated maxillofacial disorder, with both genetic and environmental factors contributing to its etiology. Now, it is accepted by most researchers that MP is a polygenic disorder. Polygenic inheritance refers to the inheritance of a phenotypic trait that can be attributed to two or more susceptibility genes. Our results indicated that the main effect gene may not be included in the NOTCH signaling pathway. Future studies with larger sample sizes, more comprehensive genome coverage, and in other population are required to replicate these findings. We will continue to collect more samples, which may take us additional time.

\section{Conclusion}

The genetic mechanisms of MP are complex. In this study, we identified some variants in the NOTCH signaling pathway that may be associated with MP. We found that rs1051415 in an exon of JAG1 was significantly related to PC1 $\left(P=3.608 \times 10^{-4}\right)$, which corresponded to the sagittal mandibular position towards the maxilla. Forty-one other variants were associated with PC1 -5 . We also identified 6 variants associated with MP and an array of common variants associated with single cephalometric parameter, although not significant after multiple corrections. And rare variants in EP300 showed association with MP. Future studies with larger sample sizes, more candidate genes, and in other population are required to replicate these findings, and further functional studies are also warranted.

\section{Supplementary Information}

The online version contains supplementary material available at https://doi. org/10.1186/s13005-021-00268-0.

\section{Additional file 1. \\ Additional file 2. \\ Additional file 3. \\ Additional file 4. \\ Additional file 5. \\ Additional file 6.}

Additional file 7: Figure S1. Three SNPs (rs1051415 in an exonic region of JAG1; rs75236173 in the $3^{\prime}$-UTR of NUMB; rs1044006 in an exonic region of NOTCH3) in six randomly selecting samples (including three cases and three controls) were validated by Sanger sequencing. The three cases were $\mathrm{C} 02, \mathrm{C} 03$ and $\mathrm{C} 8$, while the three control samples were A8, A42 and A43. The black arrows represent the polymorphism sites.

\section{Acknowledgements}

We are indebted to the participants for providing an excellence study sample, and we appreciate the dentists who performed the clinical examinations.

\section{Authors' contributions}

Xianzhuo Han: Writing- Original draft preparation, Validation. Xueyan Xiong: Data curation, Software Visualization, Investigation. Xiujuan Shi: WritingReviewing and Editing, Fengshan Chen: Conceptualization, Methodology, Supervision. The author(s) read and approved the final manuscript.

\section{Funding}

This work was supported by the National Natural Science Foundation of China (No. 81371129 and 81670973). 


\section{Availability of data and materials}

All data generated or analysed during this study are included in this published article and its supplementary information files.

\section{Declarations}

\section{Ethical approval and consent to participate}

INCLUDE the reference number.

This study was approved by the Human Ethics Committee and was conducted according to Declaration of Helsinki principles, and all participants gave written informed consent, the reference number is 2010KQ-01.

\section{Consent for publication}

Not applicable.

\section{Competing interests}

The authors declare no potential conflicts of interest with respect to the authorship and/or publication of this article.

\section{Author details}

${ }^{1}$ Department of Orthodontics, School and Hospital of Stomatology, Shanghai Engineering Research Center of Tooth Restoration and Regeneration, Tongji University, Middle Yanchang Road, 399 Shanghai, P.R. China. ${ }^{2}$ Department of Stomatology, Shanghai East Hospital Affiliated to Tongji University, Shanghai, China. ${ }^{3}$ Tongji University School of Medicine, Shanghai, China.

\section{Received: 30 September 2020 Accepted: 4 May 2021}

\section{Published online: 26 May 2021}

\section{References}

1. Singh GD. Morphologic determinants in the etiology of class III malocclusions: a review. Clin Anat. 1999;12(5):382-405. https://doi.org/10.1 002/(SICI)1098-2353(1999)12:5<382::AID-CA9>3.0.CO;2-0

2. da Fontoura CS, Miller SF, Wehby GL, Amendt BA, Holton NE, Southard TE, et al. Candidate gene analyses of skeletal variation in malocclusion. J Dent Res. 2015;94(7):913-20. https://doi.org/10.1177/0022034515581643.

3. Guan X, Song Y, Ott J, Zhang Y, Li C, Xin T, et al. The ADAMTS1 gene is associated with familial mandibular Prognathism. J Dent Res. 2015;94(9): 1196-201. https://doi.org/10.1177/0022034515589957.

4. Cruz RM, Krieger H, Ferreira R, Mah J, Hartsfield J Jr. Oliveira S. major gene and multifactorial inheritance of mandibular prognathism. Am J Med Genet A. 2008;146a:71-7.

5. Jena AK, Duggal R, Mathur VP, Parkash H. Class-III malocclusion: genetics or environment? A twins study. J Indian Soc Pedod Prev Dent. 2005;23(1):2730. https://doi.org/10.4103/0970-4388.16023.

6. Yamaguchi T, Park SB, Narita A, Maki K, Inoue I. Genome-wide linkage analysis of mandibular prognathism in Korean and Japanese patients. J Dent Res. 2005;84(3):255-9. https://doi.org/10.1177/154405910508400309.

7. Frazier-Bowers S, Rincon-Rodriguez R, Zhou J, Alexander K, Lange E. Evidence of linkage in a Hispanic cohort with a class III dentofacial phenotype. J Dent Res. 2009;88(1):56-60. https://doi.org/10.1177/0022034 508327817.

8. Li Q, Li X, Zhang F, Chen F. The identification of a novel locus for mandibular prognathism in the Han Chinese population. J Dent Res. 2011; 90(1):53-7. https://doi.org/10.1177/0022034510382546.

9. Jang JY, Park EK, Ryoo HM, Shin HI, Kim TH, Jang JS, et al. Polymorphisms in the Matrilin-1 gene and risk of mandibular prognathism in Koreans. J Dent Res. 2010:89(11):1203-7. https://doi.org/10.1177/0022034510375962.

10. Xue F, Wong R, Rabie ABM. Identification of SNP markers on $1 \mathrm{p} 36$ and association analysis of EPB41 with mandibular prognathism in a Chinese population. Arch Oral Biol. 2010;55(11):867-72. https://doi.org/10.1016/j.a rchoralbio.2010.07.018

11. Tassopoulou-Fishell M, Deeley K, Harvey EM, Sciote J, Vieira AR. Genetic variation in myosin $1 \mathrm{H}$ contributes to mandibular prognathism. Am J Orthod Dentofac Orthop. 2012;141(1):51-9. https://doi.org/10.1016/j.ajodo.2 011.06.033.

12. Cruz C, Mattos C, Maia J, Granjeiro J, Reis M, Mucha J, et al. Genetic polymorphisms underlying the skeletal class III phenotype. Am J Orthod Dentofac Orthop. 2017;151(4):700-7. https://doi.org/10.1016/j.ajodo.2016. 09.013.
13. Ikuno K, Kajii TS, Oka A, Inoko H, Ishikawa H, lida J. Microsatellite genome-wide association study for mandibular prognathism. Am J Orthod Dentofac Orthop. 2014;145(6):757-62. https://doi.org/10.1016/j.a jodo.2014.01.022.

14. Chen F, Li Q, Gu M, Li X, Yu J, Zhang YB. Identification of a mutation in FGF23 involved in mandibular Prognathism. Sci Rep. 2015;5(1):11250. https://doi.org/10.1038/srep11250.

15. Nie X, Luukko K, Kettunen P. FGF signalling in craniofacial development and developmental disorders. Oral Dis. 2006;12(2):102-11. https://doi.org/1 0.1111/j.1601-0825.2005.01176.x.

16. Rabie ABM, Tang GH, Hägg U. Cbfa1 couples chondrocytes maturation and endochondral ossification in rat mandibular condylar cartilage. Arch Oral Biol. 2004;49(2):109-18. https://doi.org/10.1016/j.archoralbio.2003.09.006.

17. Neben $\mathrm{CL}$, Merrill AE. Signaling pathways in craniofacial development: insights from rare skeletal disorders. Curr Top Dev Biol. 2015;115:493-542. https://doi.org/10.1016/bs.ctdb.2015.09.005.

18. Feller J, Schneider A, Schuster-Gossler K, Gossler A. Noncyclic notch activity in the presomitic mesoderm demonstrates uncoupling of somite compartmentalization and boundary formation. Genes Dev. 2008;22(16) 2166-71. https://doi.org/10.1101/gad.480408.

19. Ferjentsik Z, Hayashi S, Dale JK, Bessho Y, Herreman A, De Strooper B, et al. Notch is a critical component of the mouse somitogenesis oscillator and is essential for the formation of the Somites. PLoS Genet. 2009;5(9):e1000662. https://doi.org/10.1371/journal.pgen.1000662.

20. Ramasamy SK, Kusumbe AP, Schiller M, Zeuschner D, Bixel MG, Milia C, et al. Blood flow controls bone vascular function and osteogenesis. Nat Commun 2016;7(1):13601. https://doi.org/10.1038/ncomms13601.

21. Serrano MJ, So S, Hinton RJ. Roles of notch signalling in mandibular condylar cartilage. Arch Oral Biol. 2014;59(7):735-40. https://doi.org/10.1016/ j.archoralbio.2014.04.003.

22. Shimizu T, Tanaka T, Iso T, Matsui H, Ooyama Y, Kawai-Kowase K, et al. Notch signaling pathway enhances bone morphogenetic protein 2 (BMP2) responsiveness of Msx2 gene to induce osteogenic differentiation and mineralization of vascular smooth muscle cells. J Biol Chem. 2011;286(21): 19138-48. https://doi.org/10.1074/jbc.M110.175786.

23. Chen G, Deng C, Li YP. TGF- $\beta$ and BMP signaling in osteoblast differentiation and bone formation. Int J Biol Sci. 2012;8(2):272-88. https:// doi.org/10.7150/ijbs.2929.

24. Tang GH, Rabie AB, Hagg U. Indian hedgehog: a mechanotransduction mediator in condylar cartilage. J Dent Res. 2004;83(5):434-8. https://doi. org/10.1177/154405910408300516.

25. Xue F, Wong RW, Rabie AB. Genes, genetics, and class III malocclusion. Orthod Craniofac Res. 2010;13(2):69-74. https://doi.org/10.1111/j.1601-6343.2 010.01485.x.

26. Kohn A, Dong Y, Mirando AJ, Jesse AM, Honjo T, Zuscik MJ, et al. Cartilagespecific RBPjk-dependent and -independent Notch signals regulate cartilage and bone development. Development (Cambridge, England). 2012;139: 1198-212.

27. Mead T, Yutzey K. Notch pathway regulation of neural crest cell development in vivo. Dev Dyn. 2012;241(2):376-89. https://doi.org/10.1002/ dvdy.23717.

28. Han M, Ko J, Cho T, Park W, Cheong H. A novel NOTCH2 mutation identified in a Korean family with Hajdu-Cheney syndrome showing phenotypic diversity. Ann Clin Lab Sci. 2015;45(1):110-4.

29. McDaniell R, Warthen D, Sanchez-Lara P, Pai A, Krantz I, Piccoli D, et al. NOTCH2 mutations cause Alagille syndrome, a heterogeneous disorder of the NOTCH signaling pathway. Am J Hum Genet. 2006;79(1):169-73. https:// doi.org/10.1086/505332.

30. Mašek J, Andersson E. The developmental biology of genetic notch disorders. Development. 2017;144(10):1743-63. https://doi.org/10.1242/ dev.148007.

31. Aminkeng F. DLL4 loss-of-function heterozygous mutations cause Adams-Oliver syndrome. Clin Genet. 2015;88(6):532. https://doi.org/1 $0.1111 /$ cge.12681

32. Peltonen L, Palotie A, Lange $K$. Use of population isolates for mapping complex traits. Nat Rev Genet. 2000;1 (3):182-90. https://doi.org/10.1038/3 5042049.

33. Vieira A, Modesto A, Meira R, Barbosa A, Lidral A, Murray J. Interferon regulatory factor 6 (IRF6) and fibroblast growth factor receptor 1 (FGFR1) contribute to human tooth agenesis. Am J Med Genet A. 2007;143A(6):53845. https://doi.org/10.1002/ajmg.a.31620. 
34. Xiong $X$, Li S, Cai Y, Chen F. Targeted sequencing in FGF/FGFR genes and association analysis of variants for mandibular prognathism. Medicine (Baltimore). 2017;96(25):e7240. https://doi.org/10.1097/MD. 0000000000007240

35. Shrout PE, Fleiss JL. Intraclass correlations: uses in assessing rater reliability. Psychol Bull. 1979:86(2):420-8. https://doi.org/10.1037/0033-2909.86.2.420.

36. Vázquez-Martínez ER, Varela-Fascinetto G, García-Delgado C, Rodríguez Espino BA, Sánchez-Boiso A, Valencia-Mayoral P, et al. Polymorphism analysis and new JAG1 gene mutations of Alagille syndrome in Mexican population. Meta Gene. 2014;2:32-40. https://doi.org/10.1016/j. mgene.2013.10.002

37. Humphreys R, Zheng W, Prince LS, Qu X, Brown C, Loomes K, et al. Cranial neural crest ablation of Jagged 1 recapitulates the craniofacial phenotype of Alagille syndrome patients. Hum Mol Genet. 2012;21(6):1374-83. https://doi. org/10.1093/hmg/ddr575.

38. Tavares A, Cox T, Maxson R, Ford H, Clouthier D. Negative regulation of endothelin signaling by SIX1 is required for proper maxillary development. Development. 2017;144(11):2021-31. https://doi.org/10.1242/dev.145144.

39. Liu X, Zhang C, Jing J, Peng W, Zhu S, Zou S. Role of notch signaling in the physiological patterning of Posterofrontal and sagittal cranial sutures. J Craniofac Surg. 2017;28(6):1620-5. https://doi.org/10.1097/SCS. 0000000000003721

40. Jiang R, Lan Y, Chapman HD, Shawber C, Norton CR, Serreze DV, et al. Defects in limb, craniofacial, and thymic development in Jagged2 mutant mice. Genes Dev. 1998;12(7):1046-57. https://doi.org/10.1101/gad.12.7.1046.

41. Zegan G, Dascalu C, Mavru RB, Anistoroaei D. Cephalometric features of class iii malocclusion. Rev Med Chir Soc Med Nat lasi. 2015;119(4):1153-60.

42. Serrano MJ, So S, Svoboda KK, Hinton RJ. Cell fate mediators notch and twist in mouse mandibular condylar cartilage. Arch Oral Biol. 2011;56(6): 607-13. https://doi.org/10.1016/j.archoralbio.2010.11.014.

43. Negri G, Magini P, Milani D, Colapietro P, Rusconi D, Scarano E, et al. From whole gene deletion to point mutations of EP300-positive Rubinstein-Taybi patients: new insights into the mutational Spectrum and peculiar clinical hallmarks. Hum Mutat. 2016;37(2):175-83. https:// doi.org/10.1002/humu.22922.

44. Zimmermann N, Acosta A, Kohlhase J, Bartsch O. Confirmation of EP300 gene mutations as a rare cause of Rubinstein-Taybi syndrome. Eur J Hum Genet. 2007;15(8):837-42. https://doi.org/10.1038/sj.ejhg.5201791.

45. Raj M, Boughner J. Detangling the evolutionary developmental integration of dentate jaws: evidence that a p63 gene network regulates odontogenesis exclusive of mandible morphogenesis. Evol Dev. 2016;18(56):317-23. https://doi.org/10.1111/ede.12208.

46. Yan F, Feng JY, Mou TC, Liu CY, Sun Z, Shi CJ. Effect of different mechanical loading on the expression of notch signaling pathways in growing rabbits' condylar cartilage. Zhonghua Kou Qiang Yi Xue Za Zhi. 2017;52(3):176-81. https://doi.org/10.3760/cma.j.issn.1002-0098.2017.03.010.

47. Dou XW, Park W, Lee S, Zhang QZ, Carrasco LR, Le AD. Loss of Notch3 signaling enhances Osteogenesis of Mesenchymal stem cells from mandibular torus. J Dent Res. 2017:96(3):347-54. https://doi.org/10.1177/ 0022034516680349.

48. Gripp K, Robbins K, Sobreira N, Witmer P, Bird L, Avela K, et al. Truncating mutations in the last exon of NOTCH3 cause lateral meningocele syndrome. Am J Med Genet A. 2015;167A(2):271-81. https://doi.org/10.1002/ajmg.a.36863.

49. Loomes K, Stevens S, O'Brien M, Gonzalez D, Ryan M, Segalov M, et al. Dll3 and Notch1 genetic interactions model axial segmental and craniofacial malformations of human birth defects. Dev Dyn. 2007;236(10):2943-51. https://doi.org/10.1002/dvdy.21296

50. Malavia T, Chaparala S, Wood J, Chowdari K, Prasad K, McClain L, et al. Generating testable hypotheses for schizophrenia and rheumatoid arthritis pathogenesis by integrating epidemiological, genomic, and protein interaction data. NPJ Schizophr. 2017;3(1):11. https://doi.org/10.1038/s41537017-0010-z.

51. Kopan $\mathrm{R}$, llagan M. The canonical notch signaling pathway: unfolding the activation mechanism. Cell. 2009;137(2):216-33. https://doi.org/10.1016/j. cell.2009.03.045

52. Ghassemi-Nejad S, Kobezda T, Rauch TA, Matesz C, Glant TT, Mikecz K. Osteoarthritis-like damage of cartilage in the temporomandibular joints in mice with autoimmune inflammatory arthritis. Osteoarthritis Cartilage / OARS Osteoarthritis Res Soc. 2011;19(4):458-65. https://doi.org/10.1016/j. joca.2011.01.012
53. Li Y, Jin C, Bai H, Gao Y, Sun S, Chen L, et al. Human NOTCH4 is a key target of RUNX1 in megakaryocytic differentiation. Blood. 2017.

54. Cheng R, Cai XR, Ke K, Chen YL. Notch4 inhibition suppresses invasion and vasculogenic mimicry formation of hepatocellular carcinoma cells. J Huazhong Univ Sci Technolog Med Sci. 2017;37:719-25.

55. Harishankar MK, Mohan AM, Krishnan AV, Devi A. Downregulation of Notch4 - a prognostic marker in distinguishing oral verrucous carcinoma from oral squamous cell carcinoma. Braz J Otorhinolaryngol. 2017.

56. McCright B, Lozier J, Gridley T. A mouse model of Alagille syndrome: Notch2 as a genetic modifier of Jag1 haploinsufficiency. Development. 2002;129(4):1075-82. https://doi.org/10.1242/dev.129.4.1075.

57. Casey L, Lan Y, Cho E, Maltby K, Gridley T, Jiang R. Jag2-Notch1 signaling regulates oral epithelial differentiation and palate development. Dev Dyn. 2006;235(7):1830-44. https://doi.org/10.1002/dvdy.20821.

58. Sparrow DB, Guillén-Navarro E, Fatkin D, Dunwoodie SL. Mutation of HAIRYAND-ENHANCER-OF-SPLIT-7 in humans causes spondylocostal dysostosis. Hum Mol Genet. 2008;17(23):3761-6. https://doi.org/10.1093/hmg/ddn272.

59. Manolio TA, Collins FS, Cox NJ, Goldstein DB, Hindorff LA, Hunter DJ, et al. Finding the missing heritability of complex diseases. Nature. 2009;461(7265): 747-53. https://doi.org/10.1038/nature08494.

60. Schwarz J, Cooper D, Schuelke M, Seelow D. MutationTaster2: mutation prediction for the deep-sequencing age. Nat Methods. 2014;11(4):361-2. https://doi.org/10.1038/nmeth.2890.

61. Manfredi C, Martina R, Grossi GB, Giuliani M. Heritability of 39 orthodontic cephalometric parameters on MZ, DZ twins and MN-paired singletons. Am J Orthod Dentofac Orthop. 1997;111(1):44-51. https://doi.org/10.1016/S08895406(97)70301-9.

\section{Publisher's Note}

Springer Nature remains neutral with regard to jurisdictional claims in published maps and institutional affiliations.
Ready to submit your research? Choose BMC and benefit from:

- fast, convenient online submission

- thorough peer review by experienced researchers in your field

- rapid publication on acceptance

- support for research data, including large and complex data types

- gold Open Access which fosters wider collaboration and increased citations

- maximum visibility for your research: over $100 \mathrm{M}$ website views per year

At BMC, research is always in progress.

Learn more biomedcentral.com/submissions 